\title{
PERANCANGAN ALAT UKUR TINGKAT KEKERUHAN DAN KADAR pH AIR BERBASIS MIKROKONTROLER
}

\author{
Mukhlizar $^{1}$, Rita Hartati ${ }^{2}$, Murhaban ${ }^{3}$ \\ ${ }^{1)}$ Jurusan Tarbiyah dan Keguruan, STAIN Meulaboh \\ ${ }^{2)}$ Jurusan Teknik Industri, F. TEKNIK Universitas Teuku Umar \\ ${ }^{3)}$ Jurusan Teknik Mesin, F. TEKNIK Universitas Teuku Umar \\ E-mail: ${ }^{1)}$ mukhlizaracer@gmail.com, ritahartati@utu.ac.id ${ }^{2)}$,murhaban@utu.ac.id ${ }^{3)}$
}

\begin{abstract}
Abstrak
Peranan air dalam kehidupan dirasa sangat penting sehingga perlu mendapat perhatian khusus dalam pengelolaan dan pemanfaatan yang baik. Peningkatan pengetahuan masyarakat tentang air yang layak dikonsumsi makhluk hidup maupun tentang air bagi usaha peternakan dan perikanan, dapat dicapai salah satunya dengan pemanfaatan alat teknologi yang mendukung. Alat teknologi yang tersedia saat ini untuk mengukur tingkat kekeruhan ialah Turbidimeter dan alat untuk mengukur kadar $\mathrm{pH}$ ialah $\mathrm{pH}$ Meter. Kedua alat tersebut memiliki bentuk dan fungsinya masing-masing sehingga terkesan sangat menyulitkan dari segi efisiensi waktu dan tenaga serta biaya. Tujuan penelitian ini adalah untuk merancang alat ukur baru berbasis mikrokontroler dengan tingkat resolusi baik untuk mengukur tingkat kekeruhan dan $\mathrm{pH}$ air sekaligus yang lebih efisien. Alat ukur berbasis mikrokontroler ini dirancang dengan menggunakan sistem sensor fotodioda dan sensor $\mathrm{pH}$. Nilai hasil uji rancangan alat ukur mikrokontroler akan dianalisa dengan menggunakan persamaan uji regresi linier sederhana terhadap nilai hasil uji alat ukur standar (turbidimeter dan $\mathrm{pH}$ meter). Penelitian ini diharapkan dapat memberikan kontribusi baru dalam inovasi teknologi yang dapat digunakan oleh masyarakat secara lebih mudah dan murah.

Penelitian ini dilakukan di UPT Laboratorium MIPA Terpadu Universitas Teuku Umar, Jalan Alue Peunyareng Kecamatan Meureubo Kabupaten Aceh Barat mulai bulan Januari sampai dengan Agustus 2018.

Berdasarkan hasil kalibrasi sensor, diperoleh nilai tegangan keluaran terhadap perubahan jarak. Nilai tegangan tersebut mengikuti persamaan $y=-0,0918 x+3,79$ sebagai hubungan nilai tegangan terhadap perubahan jarak per $1 \mathrm{~cm}$ dan $y=0,2851 x+0,0037$ sebagai hubungan tegangan terhadap nilai $\mathrm{pH}$.
\end{abstract}

Kata Kunci : pH, mikrokontroler, turbidimeter, regresi.

\section{PENDAHULUAN}

Air merupakan hal mutlak keberlangsungan kehidupan. Air sangat dibutuhkan makhluk hidup karena segala reaksi biokimia dalam tubuh makhluk hidup dapat berjalan semestinya karena adanya air. Manusia mengonsumsi air rata 


\section{Jurnal Mekanova \\ Vol 5 No. 8, April 2018 \\ ISSN : 2502-0498}

- rata adalah 2 (dua) sampai 3 (tiga) liter perhari. Air yang dikonsumsi tersebut tentu harus memiliki standar kesehatan yang baik, agar proses metabolisme dalam tubuh terlaksana dengan baik dan dapat melarutkan senyawa kimiawi yang terkandung dalam air. Air minum aman dan sehat yang layak dikonsumsi menurut Permenkes No. 492 Tahun 2010 Pasal 3 huruf 1 adalah apabila memenuhi persyaratan fisika, mikrobiologis, kimiawi dan radioaktif yang dimuat dalam parameter wajib dan parameter tambahan [1].

Air memberikan manfaat terpenting dalam menyokong kelestarian alam misalnya hutan dan pertanian. Pemanfaatan air bagi lokasi pertanian saat ini sedang giat dilaksanakan oleh pemerintah selain untuk menunjang kesuksesan program pemerintah juga untuk meningkatkan pendapatan negara dan masyarakat serta meningkatkan swasembada pangan. Selain itu, air juga dimanfaatkan bagi industri peternakan seperti tambak udang dan ikan.

Banyak sumber air yang dimanfaatkan oleh manusia mulai dari air sungai, air danau, air sumur maupun mata air di pegunungan. Air yang dimanfaatkan untuk dikonsumsi harus berbeda dengan air yang digunakan selain untuk konsumsi, baik dari segi kualitas dan senyawa kimia di dalamnya. Saat ini, banyak kemasan air yang dijual dipasaran seperti dalam bentuk gelas, botol maupun kotak. Air kemasan siap pakai tersebut cenderung dimanfaatkan oleh masyarakat perkotaan karena daya beli yang tinggi. Namun, bagi masyarakat pedesaan air yang dikonsumsi masih memanfaatkan sumber air yang ada misalnya air sumur maupun mata air dari pegunungan.

Air yang bersumber dari mata air pegunungan maupun air sumur belum memiliki nilai kadar $\mathrm{pH}$ dan tingkat kekeruhan yang dapat diketahui oleh masyarakat untuk dimanfaatkan sebagai air konsumsi. Hal tersebut dapat menimbulkan nilai kerugian bagi kesehatan tubuh dan lingkungan tempat tinggal. Apalagi jika ternyata air yang dikonsumsi tersebut menimbulkan efek negatif bagi kesehatan organ tubuh ginjal manusia seperti batu ginjal (nefrolitialisis). Menurut WHO (World Health Organization) air yang layak dikonsumsi manusia ialah yang memiliki persyaratan kualitas secara fisik diantaranya ialah tingkat kekeruhan. Tingkat kekeruhan dalam air yang terlalu tinggi akan menyulitkan proses desinfeksi (pembersihan mikroba) dalam air. Air yang layak dikonsumsi juga harus memiliki rasa yang tawar, dimana tidak terkandung nilai asam atau basa yang terlalu tinggi. Konsentrasi $\mathrm{pH}$ dalam air dipengaruhi pula oleh tingkat kekeruhan. Sehingga jika air terlalu asam atau basa maka tingkat kekeruhan air juga akan tinggi.

Peranan air dalam kehidupan dirasa sangat penting sehingga perlu mendapat perhatian khusus dalam pengelolaan dan pemanfaatan yang baik. Karenanya masyarakat perlu meningkatkan pemahaman dan wawasan dalam mengelola dan memanfaatkan air sesuai dengan kebutuhan. Peningkatan pengetahuan masyarakat tentang air yang layak dikonsumsi makhluk hidup maupun tentang air bagi usaha peternakan dan perikanan, dapat dicapai salah satunya dengan pemanfaatan alat teknologi yang mendukung.

Alat teknologi yang tersedia saat ini untuk mengukur tingkat kekeruhan ialah Turbidimeter dan alat untuk mengukur kadar $\mathrm{pH}$ ialah $\mathrm{pH}$ Meter. Kedua alat tersebut memiliki bentuk dan fungsinya masing-masing sehingga terkesan sangat menyulitkan dari segi efisiensi waktu dan tenaga serta biaya. Oleh sebab itu perlu 
suatu terobosan baru teknologi alat ukur yang dapat meningkatkan efisiensi waktu, tenaga dan biaya yang mudah digunakan oleh masyarakat dengan menggabungkan kedua fungsi alat tersebut di atas menjadi satu dengan bentuk yang lebih sederhana (portable) dan komplit yang berbasis mikrokontroler. Berdasarkan alasan tersebut maka penelitian ini akan menitikberatkan pada bagaimana rancangan alat ukur baru berbasis mikrokontroler, yang dapat digunakan oleh masyarakat luas, untuk mengukur tingkat kekeruhan dan kadar $\mathrm{pH}$ air dari sumbet air yang mereka konsumsi sehari-hari.

\section{METODE PENELITIAN}

\subsection{Rancangan Penelitian}

Penelitian ini berfokus pada perancangan alat berbasis mikrokontroler yang bertujuan untuk mengukur tingkat kekeruhan dan kadar $\mathrm{pH}$ air. Alat yang dirancang tersebut akan diteliti bagaimana tingkat akurasi dan ketepatan dalam mengukur tingkat kekeruhan dan $\mathrm{pH}$ air dari air larutan standar yang telah memiliki nilai NTU dan $\mathrm{pH}$ dari pabrikan dengan membandingkan hasil pengukuran dari alat yang diteliti dengan alat ukur standar sebagai pembanding yaitu Turbidimeter (untuk mengukur kekeruhan air) dan $\mathrm{pH}$ meter (untuk mengukur kadar $\mathrm{pH}$ ).

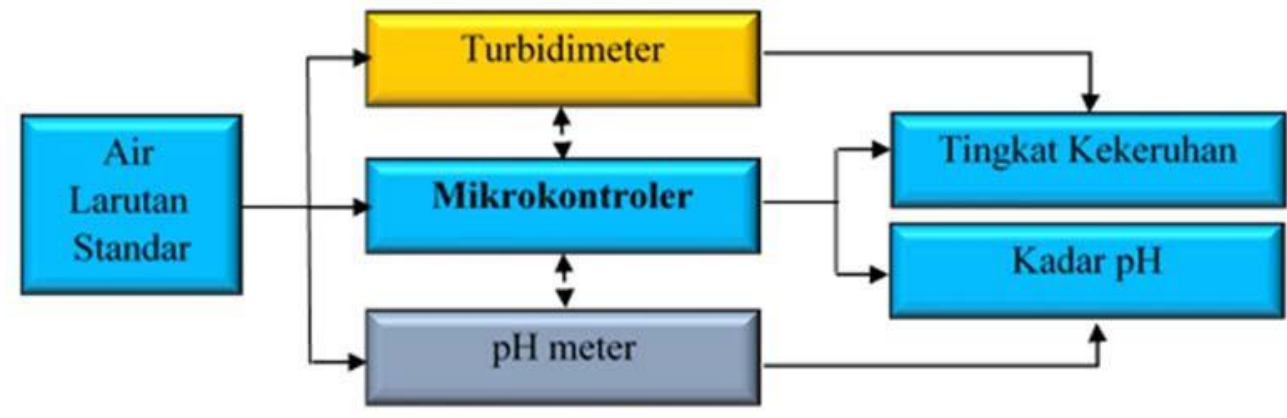

Gambar 1. Blok Diagram Prosedur Penelitian.

\subsection{Populasi dan Sampel}

Populasi serta sampel dalam penelitian adalah air larutan standar yang terdiri dari 6 kategori berbeda. Masing-masing air larutan standar memiliki nilai NTU dan $\mathrm{pH}$ yang telah dikemas dalam bentuk botol kecil.

\subsection{Teknik Perancangan Alat}

Alat yang akan dirancang terdiri atas sensor fotodioda dan $\mathrm{pH}$ sebagai masukan awal yang akan diproses oleh mikrokontroler dan hasilnya akan ditampilkan ke LCD. Skema rancangan alat dapat dilihat pada gambar 2 . 


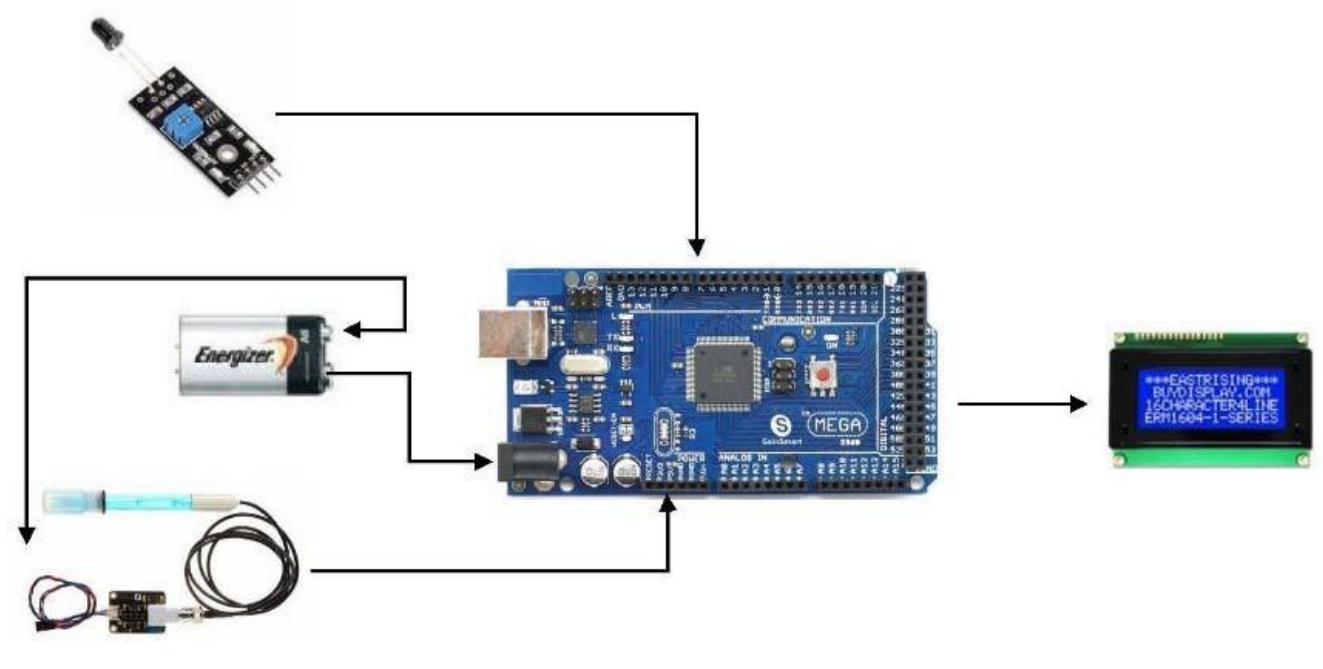

INPUT

PROSES

OUTPUT

Gambar 2. Skema Rancangan Alat.

\subsection{Teknik Pengukuran}

Hasil pengukuran alat mikrokontroler dan turbidimeter serta $\mathrm{pH}$ meter terhadap air larutan standar akan diamati dengan melihat hasil dari masing-masing alat. Hasil pengukuran dari alat mikrokontroler akan dinilai derajat hubungan kedekatan perolehan nilainya dengan perolehan nilai dari alat pembanding yaitu turbidimeter dan $\mathrm{pH}$ meter.

Penilaian derajat hubungan nilai dari masing-masing akan diuji dengan persamaan rumus regresi linier sederhana yaitu $y=a+b x, Y$ adalah nilai hasil alat ukur standar, $a$ adalah nilai konstanta dan $b$ adalah nilai hasil rancangan alat berbasis mikrokontroler, sementara $x$ adalah nilai air larutan standar yang telah disiapkan. Hasil pengukuran terhadap tingkat kekeruhan air dinilai dengan satuan NTU sedangkan untuk kadar pH dinilai dengan satuan $\mathrm{pH}$. 
Jurnal Mekanova

Vol 5 No. 8, April 2018

ISSN : 2502-0498

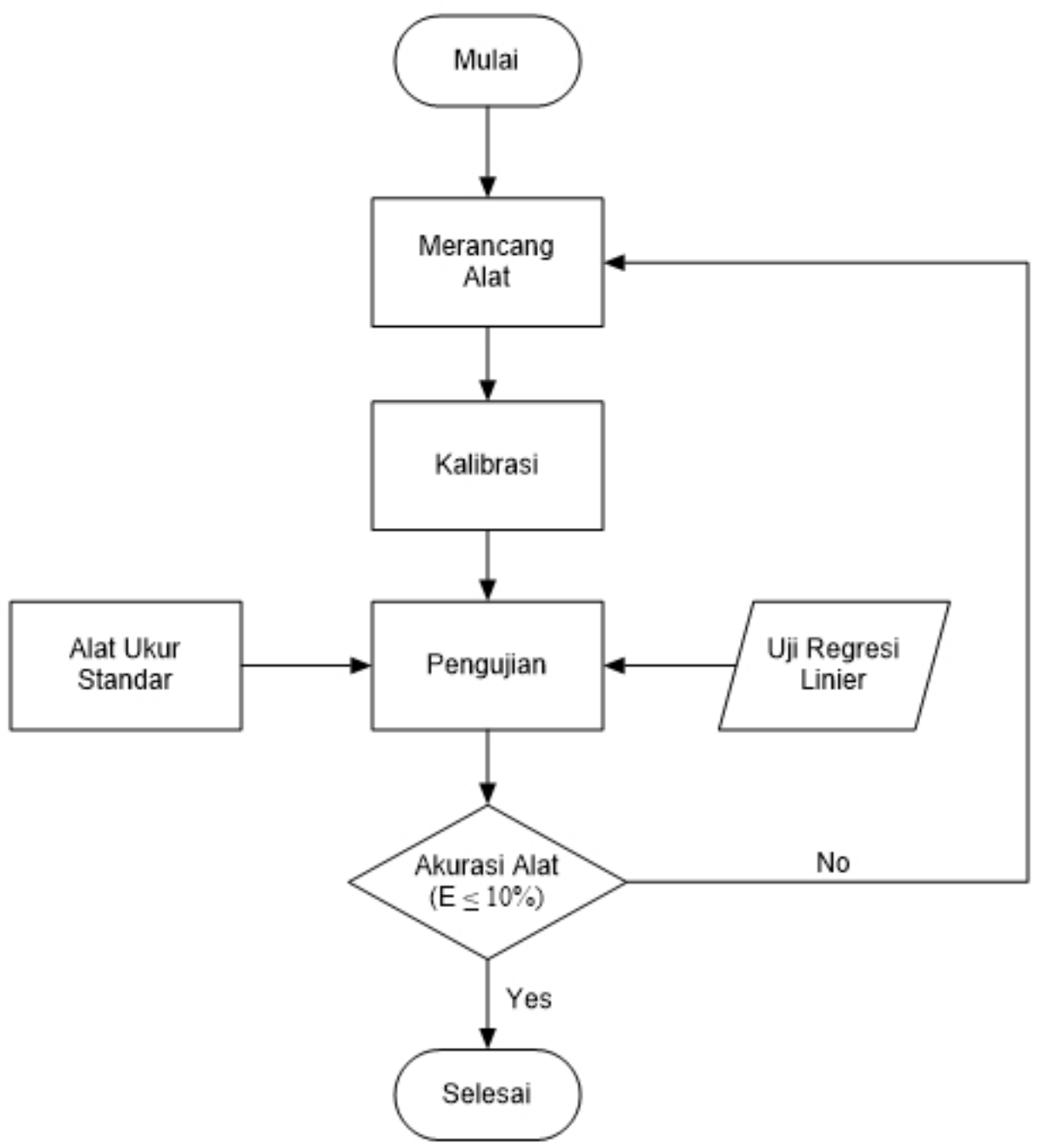

Gambar 3. Diagram Alir Tahapan Penelitian.

\section{HASIL DAN PEMBAHASAN}

\subsection{Pengukuran $\mathrm{pH}$}

Berdasarkan hasil pengukuran nilai $\mathrm{pH}$ sampel menggunakan alat standar dan alat hasil rancangan dapat dilihat pada tabel 1. sebagai berikut:

Tabel 1. Nilai $\mathrm{pH}$.

\begin{tabular}{cccc}
\hline Sampel $(\mathbf{p H})$ & Alat Standar & Alat Rancangan & Tegangan $(\mathbf{V})$ \\
\hline 2 & 2,63 & 2,45 & 0,7 \\
4 & 4,08 & 4,01 & 1,15 \\
7 & 5,78 & 6,41 & 1,83 \\
9 & 8,15 & 7,8 & 2,23 \\
10 & 8,51 & 7,96 & 2,27 \\
\hline
\end{tabular}

Sumber: Hasil pengolahan data. 


\section{Jurnal Mekanova \\ Vol 5 No. 8, April 2018 \\ ISSN : 2502-0498}

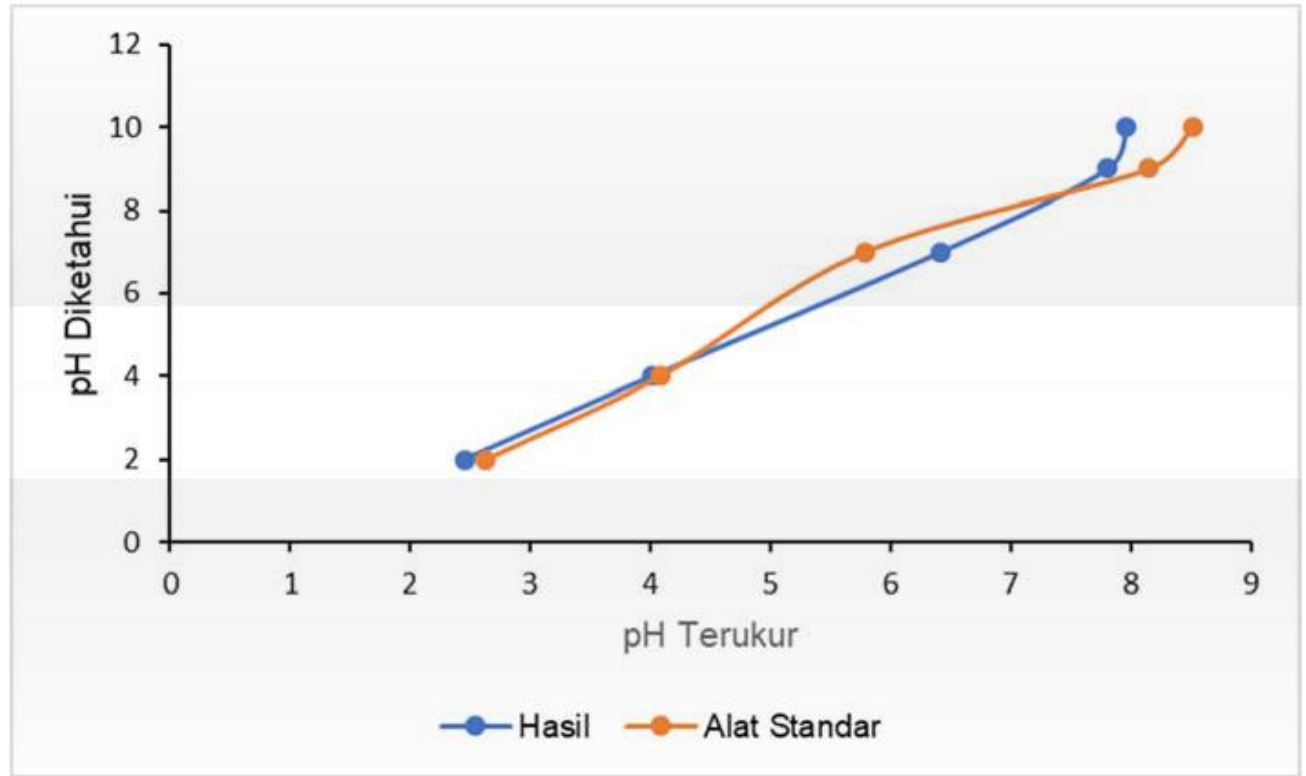

Gambar 4. Hasil pengukuran sampel pH.

Berdasarkan hasil pengukuran lima kategori sampel yang sudah diketahui nilai $\mathrm{pH}$ nya, diperoleh hasil pengukuran untuk kedua alat yang digunakan. Dari gambar 4, terlihat bahwa kenaikan nilai pH menggunakan alat hasil rancangan menunjukkan perubahan nilai secara linier.

Akurasi yang ditunjukkan oleh alat hasil rancangan, berada dibawah $10 \%$ berdasarkan hasil pengolahan data. Hal ini menunjukkan bahwa akurasi yang diinginkan dari alat tersebut sudah dipenuhi.

\section{KESIMPULAN}

Alat ukur tingkat kekeruhan dan kadar $\mathrm{pH}$ air dirancang dengan menggunakan mikrokontroler Arduino sebagai sistem utama dengan menambahkan sensor infrared dan sensor $\mathrm{pH}$ yang kompatibel dengan Arduino sebagai parameter masukan awal. Alat hasil rancangan bekerja pada tegangan 12 volt dengan arus maksimal 4 ampere. Sistem alat tersebut kemudian dirancang di dalam box (kotak) agar besifat portable dan dirancang dengan biaya seminimum mungkin. Penilaian derajat hubungan masingmasing parameter yang diukur dilakukan dengan menggunakan metode regresi linier sederhana yaitu $y=a+b x$.

Hasil pengukuran terhadap kadar $\mathrm{pH}$ cairan, diperoleh melalui persamaan $p H=3,5078 \mathrm{~V}-0,0127$ dengan tingkat kesalahan rata-rata 6\%. Pengukuran terhadap tingkat kekeruhan cairan, diperoleh melalui persamaan $N T U=51,287 \mathrm{~V}-66,374$ dengan kesalahan relatif dibawah $1 \%$.

\section{PUSTAKA}

[1] Chandra, B. 2007. Pengantar Kesehatan Lingkungan. Jakarta: Penerbit Buku Kedokteran EGC.

[2] Maemunnur, A. Fatah, dkk. 2016. Rancang Bangun Sistem Alat Ukur Turbidity untuk Analisis Kualitas Air Berbasis Arduino Uno. Fibosi (JoF), Vol.4, No. 1, April 2016

[3] Misbahudin dan Hasan, I. 2013. Analisis Data Penelitian Dengan Statistik. Jakarta: Bumi Aksara. 
Jurnal Mekanova

Vol 5 No. 8, April 2018

ISSN : 2502-0498

[4] Peraturan Menteri Kesehatan Republik Indonesia Nomor 492/Menkes/PER/IV/2010 Tentang Persyaratan Kualitas Air Minum.

[5] Slamet, J. Soemirat. 2009. Kesehatan Lingkungan. Cetakan Ke 8. Yogyakarta: Gadjah Mada University Press.

[6] Thompson. T. et. all. 2007. Chemical Safety of Drinking-water: assessing priorities for risk management, World Health Organizations Publication Data. Switzerland: WHO.

[7] Webster, J. G. \& Elen H. 2014. Measurement, Instrumentation, and Sensors. Handbook, Second Edition. New York: CRC Press

[8] Wikipedia. 2017. Sumber Daya Air.

(https://id.wikipedia.org/wiki/Sumber_daya_air, diakses tanggal 19 Juni 2017) 